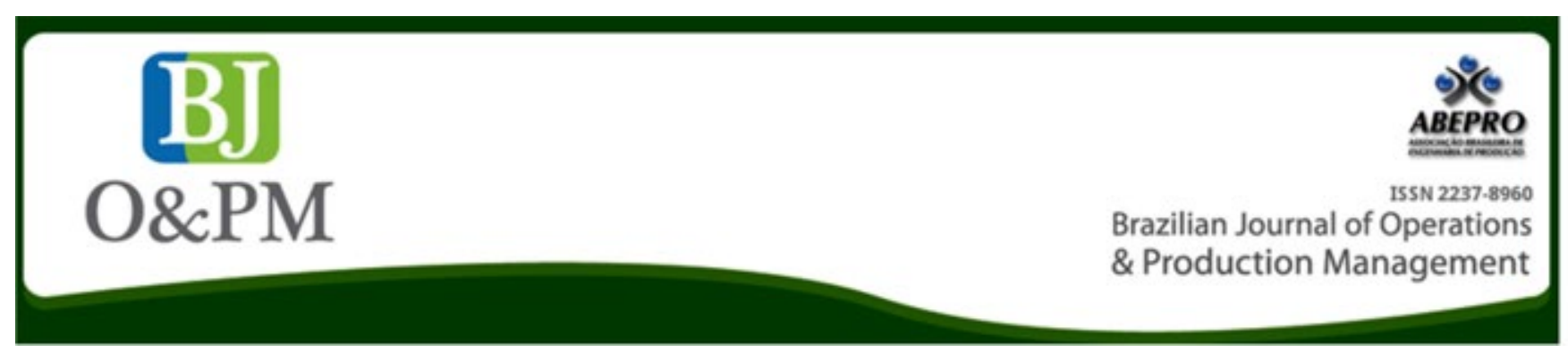

\title{
IMPROVING OPERATIONAL MEASURES IN A FINANCIAL INSTITUTE CALL CENTER: A CASE STUDY
}

\author{
Shai Rozenes ${ }^{1}$, Yuval Cohen ${ }^{1}$ \\ 1 Department of Engineering and Management of Service Systems, Afeka College of Engineering
}

\begin{abstract}
This article presents a case study that shows the impact of a proposed method of performance measures in a call center service system in one of the largest financial institutions in Israel. It proposes a policy for load-reduction in the peak hours coupled with an improvement in the automated routing of customers' calls. The case study shows the system's current state, and offers improvements to shorten the overall service time while increasing utilization of service personnel in order to decrease the abandon rate (AR) and increase service quality. The article starts by introducing the financial institute and its telephone service structure, the unique characteristic of the current service system, the different types of customers and their characteristics, the utilization of the system and emphasizes the phone call duration and AR. In addition, the article shows a simulation of the current state with an analysis of current service. It compares the current system with an alternative service system that aims at improving the main performance measures including average wait time (AWT), service personel utilization time, and customer abandon rate. The proposed system includes additional "back office" with a callback system to reduce churn rate, and improved the IVR routing. The proposed service system was simulated and all the service measurement was tested statistically. The results indicated a significant improvement in terms of service measurements between the current and the proposed system. Operators' utilization increased, while abandoning rate decreased significantly.
\end{abstract}

Keywords: Service System; Simulation; Call Center; Banking Service; Call Center Simulation; Back Office. 


\section{INTRODUCTION}

A call center is a service network in which agents provide telephone-based services. Customers who seek these services are delayed in terms of tele-queue (Brown et al., 2005). Business organizations should adopt new information model together with system development life cycle as a guideline to improve and manage information systems. Modern day call centers are increasingly complex, and have to ensure they are specialized in a variety of areas of business in order to resolve modern day knowledgeable customer complaints (Malisuwan et al, 2014).

Telephone call centers are technology-intensive operations, and interactive voice response (IVR) systems are widely used for routing calls for efficient operation. Nevertheless, often $70 \%$ or more of their operating costs are devoted to human resources. Well-run call centers adhere to a sharply defined balance between agent efficiency and service quality; to do so, they use queuing-theoretic models (Demiriz, Kula, Akbilek, 2009), as well as simulation technics (Mehrotra et Fama, 2003).

Mathematical models based on statistics are commonly used for modeling the system behavior (Gross et al, 2008; Hillier et Lieberman, 2015; Taha, 2010; Winston et Goldberg, 2004). The results of these models support the decision relating to the number of working agents, the waiting time required for a customer to be served, and the length of time customers are willing to wait on hold before they hang up the phone and abandon the queue (Aksin, Armony, Mehrotra, 2007). In practice, the number of operators is a decision-making parameter, which can be increased or decreased to attain the desired efficiency-quality trade-off (Ren et Zhou, 2008). The problem of estimating delays experienced by customers with different priorities, and the determination of the appropriate delay announcement to these customers, in a multi-class call center with time varying parameters, abandonments, and retrials was studied (Jouini et al, 2015; Taylor, 2012; Van den Schrieck, Akşin, Chevalier, 2014).

The Israeli banking system is a centralized system (Ruthenberg et Landskroner, 2008) and there are only a handful of competitors in the market. Therefore, the classical business competition, which resides between rival businesses, is almost nonexistent in the Israeli banking market. There is no real competition over the price of commissions or interest rates. Furthermore, the main difference between banks stems from the service quality provided by each bank, which can be compared to the services of other banks. Israeli banks invest great efforts in continuous improvement of their service via personnel training and via new technological products aimed to simplify the service process to customers.
Marketing managers refer to call centers as the modern business frontier, being the focus of customer relationship management (Borst, Mandelbaum, Reiman, 2004).

\section{THE CASE STUDY}

This section describes the case study of a call center within an Israeli bank. It starts by describing the current state in the call center, and continues with its analysis and its simulation.

\section{Outline of the System}

The case study deals with the commercial customer's service telephone system of a bank. The case study bank has over 160 branches across Israel and is one of the big 5 Israeli banks.

The call center of the bank has an open workspace for operators; each operator utilizes a work station that includes a computer and a telephone that is connected to a telecom switch. The case study call center contains a supervisor station. It is connected to the organization's information systems.

The operators' job duties are:

- Determine requirements by working with customers;

- Answer inquiries by clarifying desired information; researching, locating, and providing information;

- $\quad$ Resolve problems by clarifying issues; researching and exploring answers and alternative solutions; implementing solutions; escalating unresolved problems;

- Fulfill requests by clarifying desired information; completing transactions and; forwarding requests;

- $\quad$ Sell additional services by recognizing opportunities to up-sell accounts; explaining new features;

- Maintain call center database by entering information;

- Keep equipment operational by following established procedures; reporting malfunctions;

- Update job knowledge by participating in educational opportunities;

- Enhances organization reputation by accepting ownership for accomplishing new and different requests; 
Brazilian Journal of Operations \& Production Management Volume 14, Número 1, 2017, pp. 204-209

DOI: 10.14488/BJOPM.2017.v14.n2.a8

exploring opportunities to add value to job accomplishments.

The current operation includes thirteen different queues for telephone services. Each of the thirteen queues is being processed by a dedicated team of bankers. Each queue deals with a set of defined branches from across the country. This paper focuses on one queue and on a team of bankers. The current state was simulated using discrete event simulation. This simulation was validated using historical data.

There are three major kinds of customer types defined in the call center system:

\section{Private Customers}

\section{Commercial (Business) Customers}

3. Other Customers (customers who entered the queue by mistake, i.e., wrongly routed by the IVR).

The call center operators are telephone skilled bank employees who are trained for different banking services such as: money transfers, stocks, deposits, etc. The operators' performance is not identical and they have different levels of productivity, professionalism, and service times (phone call duration).

In the current state, all customers arrive at the first queue where they are sorted to "Private", "Business" or "Other".
After being sorted, the customers are directed to the proper banker in order to receive the desired service.

\section{Data Collection}

The bank information system was used for data collection. All the phone calls are being saved in a large database on a dedicated logging system. Data for this study was sampled out of the logging system.

Data of 5000 telephone calls to the bank's telephone service that were made during January 2015 was taken out of the logging system to be analyzed. The data contained details in terms of the customer type, date and time of the telephone call, time between telephone calls and the duration of each telephone call. A sample of the data can be seen in Figure 1.

It can be noticed that the arrival rate of the different types of customers is significantly different between the three types of customers. This was checked and validated.

A major characteristic of the call center is that:

- During peak hours, there is a formation of a very long queue for all types of customers;

- During the off-peak hours, queues are very small, hence the utilization also drops.

\begin{tabular}{|c|c|c|c|}
\hline Customer Type & Date Time & Time Between Arrivals (sec) & Time of Service (sec) \\
\hline Private & 01Jan2015 8:02:42 & 0 & 117 \\
\hline Private & 01Jan2015 8:03:54 & 72 & 995 \\
\hline Private & 01Jan2015 8:04:49 & 55 & 462 \\
\hline Private & 01Jan2015 8:08:55 & 246 & 155 \\
\hline Private & 01Jan2015 8:12:19 & 204 & 188 \\
\hline Private & 01Jan2015 8:14:00 & 101 & 41 \\
\hline Business & 01Jan2015 8:20:52 & 412 & 170 \\
\hline Private & 01Jan2015 8:28:28 & 456 & 53 \\
\hline Private & 01Jan2015 8:28:45 & 17 & 142 \\
\hline Private & 01Jan2015 8:32:05 & 200 & 62 \\
\hline Other & 01Jan2015 8:34:47 & 162 & 167 \\
\hline Private & $01 J a n 20158: 36: 30$ & 103 & 162 \\
\hline Business & 01Jan2015 8:36:46 & 16 & 20 \\
\hline Private & 01Jan2015 8:37:02 & 16 & 107 \\
\hline Business & 01Jan2015 8:39:01 & 119 & 143 \\
\hline Private & 01Jan2015 8:42:45 & 224 & 33 \\
\hline Business & 01Jan2015 8:49:07 & 382 & 215 \\
\hline Other & 01Jan2015 8:50:26 & 79 & 18 \\
\hline Private & 01Jan2015 8:51:01 & 35 & 389 \\
\hline Private & 01Jan2015 8:52:45 & 104 & 45 \\
\hline Private & 01Jan2015 9:03:11 & 626 & 72 \\
\hline Private & 01Jan2015 9:07:57 & 286 & 118 \\
\hline Private & 01Jan2015 9:10:03 & 126 & 348 \\
\hline Other & 01Jan2015 9:10:16 & 13 & 167 \\
\hline
\end{tabular}

Figure 1. Data sampled out of the logging system 


\begin{tabular}{|c|c|c|c|c|}
\hline $\begin{array}{c}\text { Waiting } \\
\text { Time }\end{array}$ & Average & $\begin{array}{c}\text { Half } \\
\text { Width }\end{array}$ & $\begin{array}{c}\text { Minimum } \\
\text { Value }\end{array}$ & $\begin{array}{c}\text { Maximum } \\
\text { Value }\end{array}$ \\
\hline Calls B & 65.07 & 11.50 & 0.00 & 1461.69 \\
\hline Calls O & 131.22 & NA & 0.00 & 1758.73 \\
\hline Calls P & 135.90 & 20.04 & 0.00 & 1891.98 \\
\hline
\end{tabular}

Figure 2. Waiting time

Figure 2 describes the waiting time statistics of the major customer types. Call B refers to Business customers, Calls $O$ refers to Other customers, and Calls $P$ refers to Private customers. For each customer type the statistics are: average, the confidence half interval, minimum and maximum. Waiting time during peak hours was found to be very high and substantial percentages of calls were abandoned (Figure 2). At the current state, there is no mechanism or process that takes care of the abandoned calls. The loss of these calls causes the bank to lose potential customers that may leave to another bank or financial institution.

Another aspect of the loss is reflected in poor utilization. Figure 3 shows the current system utilization divided into 4 sections: (1) Instantaneous Utilization is a time average utilization of occupied operators (out of the three available operators), (2) Number busy is the time average of the number of occupied operators, (3) Number scheduled is simply the three operators working the full shift, (4) Scheduled Utilization is the overall system utilization.

The current state is clearly not ideal: it has a very poor utilization during off peak hours and on the other hand it has also a high level of unanswered calls during peak times. Figure 3 shows overall low system utilization of $30.64 \%$ (0.3064).

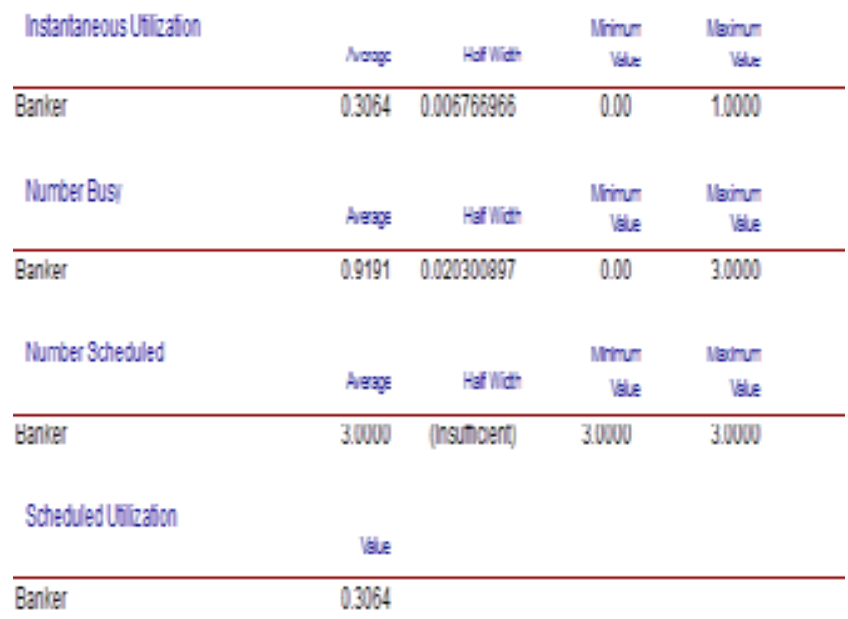

\section{Proposed Improvement}

To improve the system and increase the utilization the following steps and actions are suggested and tested within a simulation study:

Creating a Call-Back mechanism in order to take care of the abandoned phone calls:

- During rush hours part of the customers have the option to leave their phone number to be called later on;

- After the rush-hour one or two of the operators are assigned lists of call-backs

Service representatives/banker will initiate a phone call to customers who indicated that they would like a return phone call during the off-pick hours instead of waiting for a long time on the line during pick hours. This effectively lowers the abandon rate of customers, raises the system's utilization, and potentially raises the bank's profit, as abandoned calls hurt the bank's reputation and increase the potential loss of customers.

\section{Workforce planning}

For the purpose of effective human resource utilization, a careful planning process regarding the number of operators was conducted. This included an adjustment for the dynamic arrival rates as described in figure 4 .

To cope with these dynamic arrival rates the capacity of operators was aligned accordingly to increase the system's efficiency. This is reflected by a dynamic level of operators as described in Figure 5.

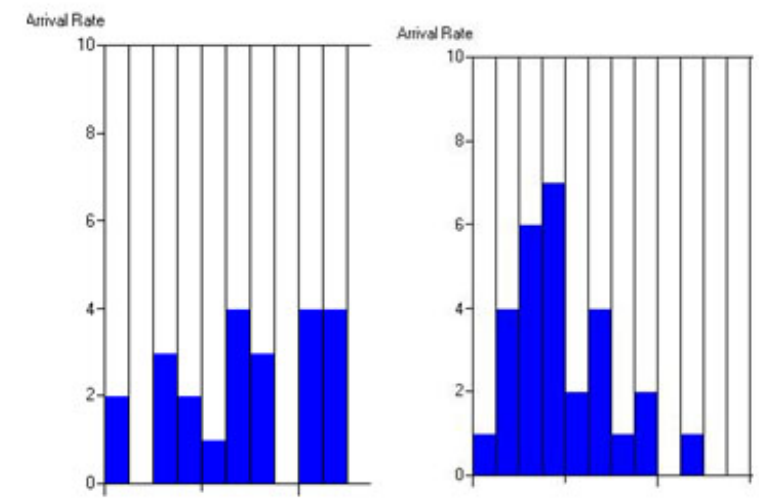

Figure 3. Current system utilization 


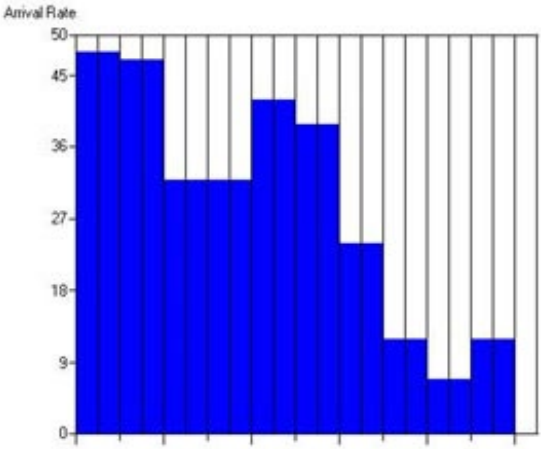

Figure 4. Customers' arrival rates per hour

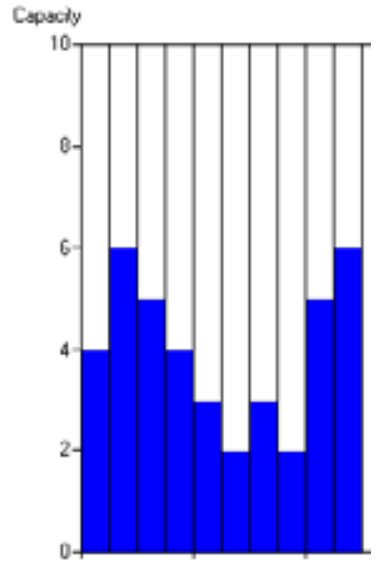

Figure 5. Capacity

The suggested simulation model shows that a change in routine and reschedule of the system can reduce payroll costs, gain goodwill, and positive reputation.

\section{Detailed procedures}

Each phone call will be checked for the possibility to continue the desired operation via a back-office representative in order to shorten the phone call duration.

During field observations, we have noticed that $15 \%$ of private customers and $10 \%$ of business customers required back-office services to complete their desired actions. This improved the service performance of the call center.

The managerial decision was to route a private customer call after 3 minutes wait to the callback list, and end the call. For business customers, the decision was to rout waiting calls after 2 minutes for the call back list. Increasing back-office services decreased the maximum waiting time for private and business customers. This includes the time from customer's phone pick up until it has been answered by the representative.
Information about new customers who entered the queue by mistake (part of "other" customers) is automatically registered in a dedicated "Sales Database", and transferred to the sales department as a "lead" of a potential new customer.

This mechanism of recruiting new customers has a critical importance to the marketing and sales of the bank. Thus, as soon as new potential customers are diagnosed in the system, a very high priority is set to save and transfer them to the sales department, thus the sales person can contact them and suggest new activities.

The utilization of the system contains several important factors that are not related directly to the workload. These include absenteeism, turnover, burnout, training, maintenance etc. In this study, all of these factors were included.

Waiting time decreased due to a call-back and back-office modules. This reduction of time is significant compared to the basic simulation, especially for the private customers, reducing almost $50 \%$ of the time.

This could be seen in Figure 6 and Figure 7.

\begin{tabular}{|c|c|c|c|c|}
\hline $\begin{array}{c}\text { Waiting } \\
\text { Time }\end{array}$ & Average & Half Width & $\begin{array}{c}\text { Minimum } \\
\text { Value }\end{array}$ & $\begin{array}{c}\text { Maximum } \\
\text { Value }\end{array}$ \\
\hline Calls B & 54.43 & 4.40 & 0.00 & 1282 \\
\hline Calls O & 43.96 & 3.10 & 0.00 & 1147 \\
\hline Calls P & 38.54 & 1.31 & 0.00 & 1262 \\
\hline Calls CB & 118.30 & 9.56 & 0.00 & 1154 \\
\hline
\end{tabular}

Figure 6. Simulation results for call-back system waiting time

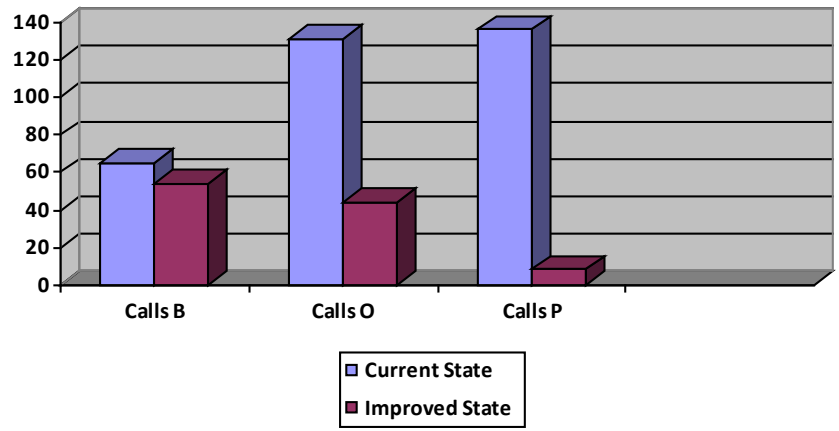

Figure 7. Simulation results for call-back system waiting time

Smaller waiting time means more satisfaction and willingness to do business with this organization. Adding a callback queue to the system made a significant decrease in the number of waiting customers. This could be seen in figure 7 .

Instantaneous utilization increased by $70 \%$ from 0.306 to 0.51 , meaning that low activity hours are now utilized to call back customers to serve them. 
Customer churn was reduced from 150 in the original state to 82 churns in the improved state. This is almost $46 \%$ reduction in terms of churn rate.

\section{CONCLUSIONS}

As mentioned, this project deals with two major issues: the first is to increase system utilization and the second is to reduce customer churn by decreasing waiting time and checking for available queue before transferring to the callback system.

Intensive simulation study was performed and results show these parameters have been improved. The call-back system is designed to reach the customer within 2 hours. This tight time-window is crucial for both customer satisfaction and relevancy of the call (Armony et Maglaras, 2004). Customer satisfaction is a crucial parameter which reduces the churn rate in this study and correlates the same phenomenon in other studies (e.g. Mandelbaum et Zeltyn, 2009; Caldwell et Howard, 2012).

To conclude, the designed callback mechanism improved the following parameters:

- The duration of the customers' waiting time.

- The number of churns (customers that abandoned their calls prematurely)

- The customer's experience navigating through the IVR

- The number of times the customer was transferred before being connected with an agent who was able to meet their needs.

Future research should give a quantitative and qualitative perspective on the timing of directing a call to the callback list. A comprehensive sensitivity analysis of the timing is essential for this purpose.

\section{REFERENCES}

Aksin, Z., Armony, M., \& Mehrotra, V. (2007). The modern call center: A multi-disciplinary perspective on operations management research. Production and Operations Management, 16(6), 665-688.

Armony, M., \& Maglaras, C. (2004). On customer contact centers with a call-back option: customer decisions, routing rules, and system design. Operations Research, 52(2), 271292.
Borst, S., Mandelbaum, A., \& Reiman, M. I. (2004). Dimensioning large call centers. Operations Research, 52(1), 17-34.

Caldwell, N., \& Howard, M. (2012). Procuring complex performance: Studies of innovation in product-service management. Routledge.

Demiriz, A., Kula, U., \& Akbilek, N. (2009). A framework for balanced service and cross-selling by using queuing science. Journal of Intelligent Manufacturing, 20(2), 249-257. http:// doi.org/10.1007/s10845-008-0232-z

Gross, D., Shortie, J. F., Thompson, J. M., \& Harris, C. M. (2008). Fundamentals of Queueing Theory (4th ed.). John Wiley $\&$ Sons.

Hillier, F., \& Lieberman, G. (2015). Introduction to Operations Research, McGraw Hill (9th ed.). New York: McGraw-Hill.

Jouini, O., Akşin, O. Z., Karaesmen, F., Aguir, M. S., \& Dallery, Y. (2015). Call Center Delay Announcement Using a Newsvendor-Like Performance Criterion. Production and Operations Management, 24(4), 587-604.

Malisuwan, S., Madan, N., Kaewphanuekrungsi, W., \& Petchinda, N. (2014). Adoption of New Information Economics for Informational System Development in Modern Day Call Center. International Journal of Trade, Economics and Finance, 5(1), 52.

Mandelbaum, A., \& Zeltyn, S. (2009). Staffing many-server queues with impatient customers: constraint satisfaction in call centers. Operations Research, 57(5), 1189-1205.

Mehrotra, V., \& Fama, J. (2003). Call center simulations: call center simulation modeling: methods, challenges, and opportunities (pp. 135-143). Presented at the Proceedings of the 35th conference on Winter simulation: driving innovation, Winter Simulation Conference.

Ren, Z. J., \& Zhou, Y.-P. (2008). Call center outsourcing: Coordinating staffing level and service quality. Management Science, 54(2), 369-383.

Ruthenberg, D., \& Landskroner, Y. (2008). Loan pricing under Basel II in an imperfectly competitive banking market. Journal of Banking \& Finance, 32(12), 2725-2733.

Taha, H. A. (2010). Operations Research: An Introduction (9th ed.). Prentice Hall.

Taylor, J. W. (2012). Density forecasting of intraday call center arrivals using models based on exponential smoothing. Management Science, 58(3), 534-549.

Van den Schrieck, J.-C., Akşin, Z., \& Chevalier, P. (2014). Peakedness-Based Staffing for Call Center Outsourcing. Production and Operations Management, 23(3), 504-524. http:// doi.org/10.1111/poms.12049

Winston, W. L., \& Goldberg, J. B. (2004). Operations research: applications and algorithms (Vol. 3). Duxbury press Boston. 